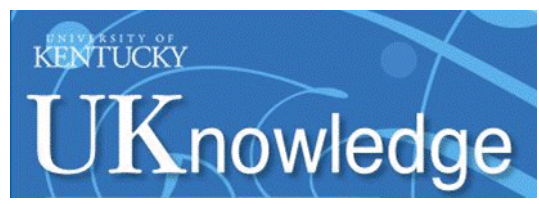

University of Kentucky

UKnowledge

\title{
The Centrality of Disclosure Decisions to the Illness Experience for Youth with Chronic Conditions: A Qualitative Study
}

\author{
Roberta Lynn Woodgate \\ University of Manitoba, Canada \\ Pauline Tennent \\ University of Manitoba, Canada \\ Sarah C. Barriage \\ University of Kentucky, sarah.barriage@uky.edu \\ Nicole Legras \\ University of Manitoba, Canada
}

Follow this and additional works at: https://uknowledge.uky.edu/slis_facpub

Part of the Health Psychology Commons, and the Library and Information Science Commons

Right click to open a feedback form in a new tab to let us know how this document benefits you.

\section{Repository Citation}

Woodgate, Roberta Lynn; Tennent, Pauline; Barriage, Sarah C.; and Legras, Nicole, "The Centrality of Disclosure Decisions to the Illness Experience for Youth with Chronic Conditions: A Qualitative Study" (2020). Information Science Faculty Publications. 75.

https://uknowledge.uky.edu/slis_facpub/75

This Article is brought to you for free and open access by the Information Science at UKnowledge. It has been accepted for inclusion in Information Science Faculty Publications by an authorized administrator of UKnowledge. For more information, please contact UKnowledge@lsv.uky.edu. 


\section{The Centrality of Disclosure Decisions to the Illness Experience for Youth with Chronic Conditions: A Qualitative Study}

Digital Object Identifier (DOI)

https://doi.org/10.1177/1359105320962242

Notes/Citation Information

Published in Journal of Health Psychology.

(c) The Author(s) 2020

This article is distributed under the terms of the Creative Commons Attribution-NonCommercial 4.0 License (https://creativecommons.org/licenses/by-nc/4.0/) which permits non-commercial use, reproduction and distribution of the work without further permission provided the original work is attributed as specified on the SAGE and Open Access page (https://us.sagepub.com/en-us/nam/openaccess-at-sage).

This article is available at UKnowledge: https://uknowledge.uky.edu/slis_facpub/75 


\section{The centrality of disclosure decisions to the illness experience for youth with chronic conditions: A qualitative study}

Journal of Health Psychology $1-13$

(C) The Author(s) 2020

\section{(c) (1) \$}

Article reuse guidelines: sagepub.com/journals-permissions DOI: 10.1 I77/I359105320962242 journals.sagepub.com/home/hpq (S)SAGE

\author{
Roberta Lynn Woodgate' (iD), Pauline Tennent', \\ Sarah Barriage ${ }^{2}$ and Nicole Legras'
}

\begin{abstract}
The aim of this paper is to illuminate findings of disclosure experiences for youth living with chronic illness using a non-categorical approach. The findings were derived from a larger qualitative study framed by social constructivist grounded theory that sought to understand youth's involvement in healthcare decisionmaking in the context of chronic illness. Fifty-four youth participated in the study, ranging from 9 to 24 years. Three main themes representing the youth's perspectives and experiences of disclosing chronic illness were identified: (I) disclosure is central to the illness experience; (2) spectrum of disclosure; and (3) navigating others' reactions to disclosure. The findings reinforce that more emphasis on decisions related to disclosing illness in research and clinical care for youth with chronic conditions is warranted.
\end{abstract}

\title{
Keywords
}

Canada, chronic illness, disclosure, grounded theory, non-categorical approach, youth

\section{Introduction}

The number of children and youth ${ }^{1}$ living with a chronic illness is steadily increasing (Leeman et al., 2016; Perrin et al., 2014; Vos et al., 2015). Pediatric chronic illness is generally characterized by incurability or duration of at least 3 months, limitations in age-appropriate function and activities, and need for health services extending beyond routine care (van Der et al., 2007). Youth with chronic illness can consistently experience inferior physical (Silva et al., 2019), psychological (Ahola Kohut et al., 2016; Pinquart, 2017; Reaume and Ferro, 2019), and social and emotional (Denny et al., 2014; Maes et al., 2017; Russell et al., 2019) well-being compared to their healthy peers. In addition, youth with childhood-onset chronic illness may suffer from poorer educational and vocational outcomes compared to youth who are healthy and/or experience later-onset of illness (Lum et al., 2017; Maslow et al., 2011; Yoder and Cantrell, 2019).

\footnotetext{
'University of Manitoba, Winnipeg, MB, Canada ${ }^{2}$ University of Kentucky, Lexington, KY, USA

Corresponding author:

Roberta Lynn Woodgate, Canadian Research Chair (Tier I) in Child and Family Engagement in Health Research and Healthcare; Principal Investigator, IN•GAUGE; Professor, Child Health and Illness, Rady Faculty of Health Sciences, College of Nursing, University of Manitoba, 89 Curry

Place, Winnipeg, MB R3T 2N2, Canada.

Email: Roberta.Woodgate@umanitoba.ca
} 
Diagnosis of a chronic illness is a significant disruption in "normal" life trajectory (Sligo et al., 2019); youth must reconsider their everyday life, their identity, relationships (Ahola Kohut et al., 2016), and their future (Beacham and Deatrick, 2015; Kirk and Hinton, 2019; Lambert and Keogh, 2015). Youth living with chronic illness and their families face many decisions; some periodic (e.g. treatment course) and others on a daily basis (e.g. disclosure) (Miller, 2009). Literature examining pediatric chronic illness decision-making reveals dissimilarities in parent-youth perceptions, particularly regarding the illness's impact on the youth's life and who adopts the main responsibility for illness management (Heyduck et al., 2015). With the use of age/developmentallyappropriate education approaches to illness self-management (Saxby et al., 2019), youth are capable of making effective decisions about illness management (Krockow et al., 2019). Recognizing youth as active participants in illness decisions is associated with greater agency (Law et al., 2014; Wakefield et al., 2011).

While literature supporting chronically-ill youth's decision-making in the areas of healthcare management is increasing, youth decision-making in the context of illness disclosure has been a lesser focus. To date, literature examining youth's disclosure of chronic illness has been conditionspecific. Research has focused on conditions such as epilepsy (Benson et al., 2015a, 2015b), cystic fibrosis (Berlin et al., 2005), sickle cell disorder (Dyson et al., 2010), and inflammatory bowel disease (Barned et al., 2016). Human immunodeficiency virus (HIV) is perhaps the most extensively researched in terms of youth disclosure literature (e.g. Blake et al., 2012; Fair and Albright, 2012; Galano et al., 2017; Greene and Faulkner, 2002; Lee et al., 2015; Siu et al., 2012).

Although existing literature provides some insight into the experience of youth living with specific conditions such as HIV, the wide range and relative rarity of chronic illnesses calls for a non-categorical approach to the experience of youth disclosure. Only recently has disclosure research been extended to youth with various chronic conditions (Kaushansky et al., 2017).
The aim of this paper is to illuminate findings of disclosure experiences for youth living with chronic illness using a non-categorical approach. A non-categorical approach extends beyond a biomedical diagnosis, and allows us to see common threads in the psychosocial experience of individuals living with diverse chronic illnesses (Gannoni and Shute, 2009; Stein and Jessop, 1989; Stein and Silver, 1999). The findings were derived from a larger qualitative study that sought to understand youth's involvement in healthcare decision-making in the context of chronic illness.

\section{Methods}

\section{Design}

A 3-year qualitative research study framed by social constructivist grounded theory was undertaken. Social constructivist grounded theory, as described by Charmaz $(1983,2000)$ seeks to understand social processes, placing emphasis on the interaction between the researcher and the participant as the means of producing the data, including the "meanings that the researcher observes and defines" (Charmaz, 1995: 35).

\section{Participants}

The study took place in Winnipeg, Canada. Participants were recruited at a pediatric hospital using the maximum variation technique of purposive sampling. The aim was to arrive at a diverse sample that captures the complexity, depth, and variation of youth living with a chronic illness (Morse and Field, 1995; Sandelowski, 1995). Snowball sampling was also utilized. Recruitment and analysis occurred concurrently, with recruitment ending once redundancy or data saturation was achieved. In total, fifty-four youth participated in the study, ranging in age from 9 to 24 years with the mean age of 15 years. $37.1 \%$ of the participants $(n=$ 20) received a diagnosis before their sixth birthday; $29.7 \%$ between the ages of $7-12(n=16)$; and the remaining $33.5 \%(n=18)$ after their 12th birthday, but before their 18th birthday. A 
roughly equal number of males $(44.4 \%)$ and females $(55.6 \%)$ participated in the study. The chronic illnesses of youth were varied and included as a primary diagnosis: arthritis, asthma, benign brain tumours, Crohn's/Colitis, cystic fibrosis, diabetes, heart conditions, kidney condition, and liver conditions. There were no discernible gender differences noted.

\section{Data collection}

Youth took part in open-ended interviews in a location of their choosing. The interviews were conducted by two research assistants trained and supervised by the first author. An interview guide was used that included questions such as "what it was like to have a chronic illness," and "what are the types of decisions that you are required to make" but did not have any questions related to the decision to disclose illness. The interview questions were developed by the researcher (first author) based on literature and extensive experience of working with youth with chronic illness.

Open-ended interviews afforded the opportunity to gather from youth rich and detailed descriptions of the meaning of, and experience of disclosure in the context of living with a chronic illness. The open-ended method adopted a flexible approach in order to provide youth the opportunity to share the most salient aspects of their experiences and areas not anticipated by the research team (Barbour, 2008; Morse and Field, 1995) (in this case, their experiences in disclosing their illness to others).

All interviews were digitally recorded and transcribed verbatim to preserve their authenticity. Field notes describing verbal and nonverbal behaviors, communication processes, rapport, interview context, and any procedural problems that transpired were completed after each interview.

\section{Data analysis}

As is common in qualitative research, data analysis occurred concurrently with data collection. Following the constructivist grounded theory approach, data was initially subject to a thematic analysis (Charmaz and Belgrave, 2012).
Interview transcripts and field notes were imported into NVivo (QSR International Pty Ltd., 2018) and carefully reviewed line-by-line for significant statements independently by the first two authors (RLW and PT). Attention was given to exploring similarities and differences between participants. Labels or phrases were assigned to each segment of the content (open coding). These codes were then collated and discussed among RLW and PT for inter-coder agreement. Any discrepancies or uncertainty of codes were resolved via discussion among all four authors until consensus was achieved. Codes and collated data were examined for broader patterns of meaning, delineated and formed into thematic statements. The units of meanings and thematic statements were further reviewed until themes representing the youth's experiences were finalized with reference to the existing literature on disclosure experiences of youth. Ongoing discussions among the researchers (i.e. all four authors) also provided them the opportunity to take a reflexive stance on their own worldview, address their assumptions and disagreements, and deal with any biases (Lincoln and Guba, 1985).

\section{Ethical considerations}

The study received ethical approval from the Education/Nursing Research Ethics Board at the researchers' university and adhered to the tenets of the Declaration of Helsinki. For youth participants under 18 years of age, written consent was obtained from their parents and assent from the youth. For those youth 18 years and older, written consent was obtained from them. Throughout the study, we strived to ensure that ethical standards were maintained, which included informing youth participants about confidentiality and the right to terminate their involvement in the study any time. All youth received an honorarium for their participation in the study.

\section{Findings}

The youth who participated in this study were diagnosed with diverse conditions and experienced diversity in decisions around healthcare 
management. Despite the diversity, decisions related to disclosing illness were of the most salient decision-making experiences to youth. Three main themes representing the youth's perspectives and experiences of disclosing illness were identified: (1) disclosure is central to the illness experience; (2) spectrum of disclosure; and (3) navigating others' reactions to disclosure. Taken together, all three distinct themes result in a compelling picture of youth's experiences of disclosing illness.

\section{Disclosure is central to the illness experience}

Youth in this study viewed the disclosure process as one of the greatest challenges of having a chronic illness as this 16-year-old female with a recurring brain tumor reinforced:

Well I think the hardest thing is telling people about it [tumour]. . . I found that part very hard like explaining to them. I didn't really tell that many people cause it's not the hugest deal in the world. But it was one of the hardest things to try and like explain it to people but they don't understand cause they didn't know me when it first happened.

Similarly, another participant, who was 18 years old at the time of the interview with renal failure, described the decision to disclose as the "background of my life."

Youth described participating in disclosure from a young age, progressively assuming more responsibility and control of the process as they matured and became increasingly socially independent from their parents. Youth wanted to maintain control over how disclosure would take place, be it through their own disclosure or through a proxy. Youth spoke of the importance of maintaining choice, where possible, in the disclosure process. This sense of choice was related to their need to maintain control over one's body and illness when able in the face of no choice or limited options in other areas of health decisionmaking. Teenage participants emphasized personal privacy, and in assuming control over chronic illness disclosures, described a changing reluctance to disclose in different settings. A 17-year-old with rheumatoid arthritis noted:

When I was younger all the teachers were told that I had arthritis so they were very understanding. Like, if I couldn't go to gym class or whatever and that would be okay with them. But then I got to high school and none of the teachers knew. I never said anything.

Disclosure was a staged process that required significant work including ongoing monitoring to track to whom they had disclosed and what, in their different lived spaces. There was also preparatory work in creating and rehearsing a mental disclosure script that was often overlooked. Some youth commented that they had "rehearsed" this script in front of others, or that they would share only partial information in order to gauge reactions from others. The more that young people needed to explain both in terms of how long the need for disclosure existed, as well as how often disclosure was required, the greater a burden the work of disclosing became. While the disclosure process may transform over time, the act of disclosure was always central. Youth's narratives reinforced that disclosure was not a one-time event, but rather an ongoing process, with choice and privacy being key.

\section{Spectrum of disclosure}

Young people living with chronic illness disclosed in different ways to different audiences. While many participants expressed the idea that their diagnosis was not a secret, it also was not knowledge to be broadcast widely, shared prematurely, or without purpose. Some youth preferred nondisclosure and opted to conceal their illness or condition from others, while others chose to openly share their diagnosis. Still others may engage in selective or conditional disclosure, using a system of rules and restrictions determined by the youth to guide their decisions in considering not only who to tell, but also what and how much information to share. For many participants, it was important to know what was being done with the information being disclosed. 
Concealment and non-disclosure. There were times when youth decided not to disclose their health condition. They used a number of strategies in their attempts to mitigate the differences they experienced living with their health condition. Many youth were willing to spend considerable energy pushing themselves beyond their physical limits in order to "act normal." In this way, the decision not to disclose was to appear as normal as possible. A 17-year-old with asthma, anxiety, and depression shared that she exerted considerable energy while engaging in extracurricular activities, all in an attempt to appear as "normal": "So I just push myself every game and then some games I'd play the whole game and sometimes I'd stop halfway through, but the point was that I kept trying."

In order to maintain a sense of normalcy, young people would prepare for those everyday activities that could result in their health conditioning worsening. For example, one youth with Crohn's disease shared a story of the predicament he faced in going for dinner to his girlfriend's house. He knew the food was going to be spicy, and so instead of declining the food, he prepared by taking medicines beforehand that would allow him to participate. In this case, he wanted to maintain a sense of normalcy in his relationship. Another youth who had lived many years with cystic fibrosis shared that they disclosed as little as possible in order to reduce the effort required in the disclosure process, stating "I'm usually just like they're pills. . .end of story. . ..Cause it's too complicated to get into."

Others, at times, would deliberately conceal their illness. They would hide how they were truly feeling, avoid conversations or questions about their condition, come up with excuses to explain absences, forego accommodations, and withdraw from social activities. These participants also avoided displaying markers of their illness (i.e. concealing medical ID jewelry), and at times avoided entering those public places (i.e. specialized medical clinics) that could potentially associate them with their illness. In such situations, participants were willing to sacrifice aspects of their health in order to appear healthy and "normal," even if only for a short period of time. Some participants discussed making calculated choices to be untruthful or selectively truthful as a way to maintain their privacy. In deciding not to disclose, there was emotional work including feelings of guilt and stress. One 15-year-old who lived with a chronic illness shared that the pressure to "keep it in" resulted in heightened emotions including anger and changed who he was. Another 19-year-old living with juvenile rheumatoid arthritis, who preferred not to disclose their condition to their peers, shared:

Participant: I just don't want to spend all my time explaining to them how I feel or like why I wasn't there cause like sometimes it's embarrassing, I don't know it's just weird. . . like having to make up an excuse why you're not going out and it's really just because like I'm exhausted and I don't feel well and like I'm sore I just want to have a bath and go to bed. . .

Interviewer: So what kinds of things do you say?

Participant: Oh my mom doesn't want me going out tonight. . .Or like um it's a family movie night. I t's not technically lying but I do say that like I can't go out tonight I'm not allowed.

Concealment of illness and non-disclosure occurred for a number different reasons, including a sense of protecting others from knowledge of ongoing health problems and therefore having to deal with it, the need to feel "normal," a desire to avoid upsetting family members, wanting to maintain privacy and control over personal information, and preventing others from reacting in troubling ways.

Partial disclosure. For some young people, there was limited choice in disclosure, in part because 
the symptoms of the illness or the impact of treatment was visible to others. For instance, youth may feel forced to disclose if someone witnessed them having a seizure or performing acts of self-care or health management such as taking medications. Disclosure may also be triggered by changes in a youth's physical appearance, such as hair loss or scars, changes in mood or speech, or physical limitations. For instance, one youth living with multiple sclerosis, shared:

Um [on] bad days I guess especially with the walking is that a couple of friends of mine notice why are you limping, why are you limping and I'm I don't know if I mentioned, but I'm not really telling people about this. I mean a few friends know and my family knows.

In some instances, the decision to disclose and act of disclosure was undertaken without words; it was a nonverbal and passive action resulting from people around them noticing differences. Wordless disclosure, or disclosure through actions, could be problematic as it marked youth as different. As well, youth could not always control the information provided to onlookers, sometimes having no choice about resulting disclosures. However, wordless disclosure was also thought of as a way to mitigate the effort involved in disclosing by reducing the discussion needed.

The status of their illness and its treatment also played into decision to disclose. For instance, during setbacks in their health, participants shared that they had neither the energy nor the focus to put the work into disclosure. Conversely, for other participants, periods of increased symptom severity or times of frequent treatment made them more likely to disclose, as reinforced by the following account from a 17-year-old living with cystic fibrosis:

Um well my health comes first so like for sports it is difficult cause my lungs aren't quite as good as they should be. My coach like knows about my health condition. He sometimes says certain things like, "Oh ' $\mathrm{C}$ ' can't do this because, you know, she'll die." He's a joker. But he knows I can take the joke. . So my coach understands it so I may just like sit out for a couple laps or cough some stuff up and stuff.

Active, open disclosure. Some participants favored active, open disclosure to different audiences for a number of reasons, such as having accommodations made, for safety reasons, for advocacy, and for matters relating to their identity as someone living with a chronic illness. For these participants, active disclosure was a means of revealing their true selves, particularly to those they trusted. However, depending on the audience (i.e. family, close friends, acquaintances, classmates, employers), there were often different scripts to guide the process. For instance, disclosing to teachers may differ from the narrative shared during disclosure to friends. One youth, when disclosing to their teacher, was very matter-of-fact sharing only the basics, while with friends shared more of the personal impacts of their health condition. The converse also true for other participants. For participants who had multiple diagnoses, disclosure decision-making also included which diagnoses to be disclosed. A young man who lived with more than one chronic health issue felt that disclosing his allergy was acceptable to his peer group, whereas he would decline speaking about, and actively conceal, his other conditions from this same group. One of the participants elaborated on how disclosing to friends and the school takes into account many factors. Not only does she disclose differently based on setting and involvement, but also even limits the information that her close friends receive. The 17-yearold shared:

Interviewer: Do your friends know about this?

Participant: Um yeah um well my water polo friends all for sure know just because it kind of affects me in playing water polo and the trips and everything I do my medications and all that so they 
know. Um like in elementary I'm pretty sure like everyone knew, all the teachers, everyone in the my class and everything but it's (sigh) it's not something I tell. Like how do you tell someone like you become friends with it's like oh yeah I have cystic fibrosis. My closer friends at school know. They know but they don't really know what it is you know like I don't know they know I like go to the hospital every once in a while and I have to take pills when I eat.

Another youth, 12-year-old at the time of the interview, and living with diabetes shared that despite being open about her chronic illness, she did find it exhausting:

Interviewer: Um so what do you usually say [if someone asks you about your illness]?

Participant: It depends what the question is I guess, like if they ask why are you doing that then I'll explain what I'm doing and why I have to do it.

Interviewer: Are there questions that you really don't like being asked.

Participant: Yeah sometimes, just cause it takes a long time to explain. But I'm not really uncomfortable with that, like answering any of them cause I have to deal with it so whatever they might as well know too.

While youth exercised their agency to disclose, there were instances were youth felt that the performative aspect of telling their story became rote, so that disclosure occurred not in a way that was empowering them, but rather for the benefit of the listener. In these instances, their story transformed into a script that anyone could perform. Participants described disclosure in these settings as becoming more limited as a way to preserve one's energy.

Disclosure by proxy. Decision-making in the context of young people living with chronic illness is often complicated by the triangular relationship among youth, parents and healthcare professionals which often highlighted power imbalances in the relationship. Participants shared their frustrations of interactions with doctors, healthcare providers, as well as educators who spoke more to the adults accompanying them to appointments, than to the youth themselves. Additionally, participants shared that at times, they have no choice in the disclosure process when it is legislated or otherwise required, such as in the school setting. In such situations, parents would disclose their child's diagnosis for reasons related to their child's well-being. Often times, the child's voice was considered and involved in the decision to disclose. A 10-year-old participant with a heart defect shared that his mother disclosed his condition in the school setting as a means to help monitor his health and well-being, explaining:

They want to see what I do that could race my heart, like my mom gave me my teacher this little book that marks, they mark down like anything that would maybe like race my heart like in gym or something.

Limited disclosure by proxy of one's health concerns in school or emergency situations for safety reasons was tolerated, or begrudgingly accepted by youth in the study. However, participants expressed their frustration in situations whereby disclosure occurred on their behalf, without their consent or against their wishes. One participant, who was diagnosed with multiple sclerosis, shared the following:

So I told my parents sort of cause they hadn't been suspecting MS that much. ... Um and my fiancé felt that if we tell your parents we have to tell my 
parents. . . I'd made it very clear to my parents that this was personal and that they can't tell anybody and if they could respect my wishes and do not tell anybody else. My [spouse] made it a lot less clear to his parents, but [did say] this is private for her it's personal, she doesn't want you telling other people. But neither of them respected that. So their decisions to tell people I definitely don't feel like I was you know I was involved, cause I told them not to um, but they sort of went against that. . .. And then of course that changed the dynamics like I'm no longer going to share things with them unless they're directly involved. So when they were here and the ambulance took me away for the appendectomy obviously they're going to know otherwise I probably would not have told them that just cause we have different views on confidentiality.

\section{Navigating others' reactions to disclosure}

Participants described times when their disclosure was met with disbelief, creating additional issues of both a personal and sometimes bureaucratic nature, such as in the case of schools. Disbelief as a reaction to disclosure could cause tension in interpersonal relationships with regard to trust and likelihood of future disclosure. In a bureaucratic sense, receiving a response of disbelief was often manifest as the need for additional documentation for accommodation, such as providing proof of medical appointments. One teen discussed how her teacher assumed she was lazy as a result of missing classes. Disclosure was more likely to be avoided when viewed as complex, and when it required extra steps, such as the provision of proof or verification.

Some youth expressed frustration by the reactions from others. There were many cases where youth disclosed wanting to be meaningfully listened to, but instead received unsolicited advice. Even while this may be well-intentioned, having to listen to others only added to the work of disclosure and the burden of living with a health condition. A 17-year-old participant who had undergone a liver transplant shared:

So I mean at times I can get pretty frustrated with people. . My decision to not tell them due to the fact that it just gets annoying. A lot of people think that they know what they're talking about and try and give you suggestions that aren't really going to help you. Everyone's an expert. ...And it's like you just have to sit there and listen to it. You know it's have you tried this, have you tried that. So I just sit there and nod my head . . .It's just you're tired or whatever and it's they're just drumming on and on about how their great grandpa's third cousin did this so I should try it. It's not the right time to talk about their health concerns.

On the other hand, in speaking about what would encourage disclosure, some youth described disclosing to others after they made a disclosure of roughly equal weight, which gave a sense of reciprocity in the exchange.

Stigma and the anticipation of stigma was always present in youth's lifeworld shaping their decision to disclose. Stigma associated with chronic illnesses both visible and invisible by virtue of being different. Youth report concerns about both public and self-stigma as a barrier to engaging in disclosure. One young person living with multiple sclerosis shared:

I'm not really telling people about this. I mean a few friends know and my family knows in general, but just because I'm a med student I want residency and I'm just a little concerned about what people might think or not think. It's sort of a personal thing right now so that trying to sort of brush off the symptoms when astute medical students would be able to figure it out saying oh I'm fine it's no worry that can make it a bad day.

Another participant, 16 years old, who had survived a brain tumour shared:

Disclosing changes the way people treat me. I don't feel the need to tell other people but sometimes it's necessary. I just, like it's not really a big deal to me to have a chronic illness, but when I tell people they get so uptight and so sensitive and you don't really feel the need to treat me differently.

Since disclosure was seen as a process influenced by expected outcomes, the experience of 
stigma related to chronic illness and ideas of what is "normal" influenced how young people gauged possible outcomes related to disclosure. The felt stigma that produced a need to conceal, mask or cover up in order to make limitations of their illness more socially acceptable.

\section{Discussion}

The findings from this study yielded important insights into the experiences of healthcare decision-making for youth, namely illness disclosure, by using youth's own words. Most significant was the finding that regardless of the chronic illness diagnosis, decisions related to disclosing illness were of the most salient decision-making experiences to youth. The findings from this study reinforced how disclosure informs everyday life for youth with chronic illnesses. As youth are influenced by other's reactions to their disclosure, they develop various approaches for disclosure, and subsequently adopt different roles. Youth's narratives reinforces the ways in which these various roles shape how they see themselves and are perceived by others. We are all actors in our lives, however this feeling is intensified and more varied for youth with chronic illness as they choose to disclose and/or not to disclose their illness.

Disclosure is interwoven in youth's social world, how they live, and how they experience their health condition (Siu et al., 2012). The significance of disclosure in the social experience, reflected in youth's interactions with others, was often for the purpose of appearing as "normal." Youth describe the work of disclosure as constant and ongoing. The process involves many decisions regarding the audience, the content, and the amount of information shared. The multiple dimensions of the disclosure process were reflected in the results where youth negotiated complex social groups and maintained varying levels of autonomy in the choice to disclose their health status. Like many other studies, the youth's disclosure was influenced by contextual and relational factors, past experiences, and expected outcomes (Greene and Faulkner, 2002; Gronholm et al., 2017; Siu et al., 2012). While the decision and process may vary, disclosure is always a central aspect of the youth's illness experience.

Disclosure is a way for youth to tell others about themselves, specifically about their chronic illness and their health situation. For youth, managing other's knowledge and perceptions about their chronic illness has important implication for their identity (Barned et al., 2016; Kirk and Hinton, 2019). Similarly to existing research (Benson et al., 2015b), there was no one-size fits all approach to disclosure expressed by the youth. Our study found that youth disclose differently to different audiences, ranging from non-disclosure, partial and/ or selective disclosure, and full disclosure. The responses in our research study reflect that when that when young people feel different, most notably from friends and peers, it strongly influences how they participate in everyday life, manage treatment, and communicate (Lambert and Keogh, 2015). Some youth strive to reduce illness-imposed differences through non-disclosure and the suppression of illness expression. For individuals with invisible or concealable illnesses, the decision to disclose is a contentious and intentional one. However, for youth with visible signs of illness, wordless disclosure is a common and often troubling occurrence (Siu et al., 2012). Partial disclosure may be passive due signs of illness or active as method of assessing the audience's receptivity and the potential safety of full disclosure. In situations of disclosure by proxy, there is tension between balancing the physical safety of youth and/or compliance with requirements with youth's sense of social well-being as these may be mutually exclusive (Dean et al., 2015). Disclosure without youth's consent or against their wishes is very upsetting for youth, reducing their autonomy to its lowest level (Duncan et al., 2015). Some youth engaged in full disclosure, however the narratives of their disclosure still varied according to the audience. Youth engaged in preventative disclosure in hope of controlling and managing the impressions formed (Barned et al., 2016) or as a way of mitigating psychological distress associated with 
identity concealment and increasing social comfort (Kaushansky et al., 2017).

Youth's decision to disclose is influenced by the anticipated reaction of the recipient outcome (Greene and Faulkner, 2002). Negative expectations can be a result of past experiences and/or internalized stigma. When a youth's condition is not openly discussed at home and in public, youth may feel a pressure not to disclose their condition due to perceived lack of social acceptance (Admi and Shaham, 2007; Benson et al., 2015b; Lambert and Keogh, 2015). In the study, youth reported that their disclosures were met with various reactions, ranging from disbelief and/or unsolicited advice. Youth reported that they did not feel meaningfully listened to when disclosing their condition. For youth this even more pronounced by virtue of their status as minors where their voice is often dismissed or silenced.

\section{Implications}

Public and proactive disclosure by youth from an early age normalizes their condition (Kaushansky, 2017) and promotes positive outcome expectations (DeLong and Kahn, 2014). It is crucial that we respect youth's privacy and foster their agency by allowing youth with concealable illnesses to retain choice and promoting healthy disclosure experiences in youth who experience passive disclosure due to visible illness expression. Moreover, given that many youth with chronic illnesses educate themselves about their condition for the purpose of explaining and discussing it with others during disclosure (Kaushansky et al., 2017), education from providers about their condition may help develop their communication abilities and increase their self-confidence to disclose. Moreover, discussing recipient's potential reactions to disclosure increases self-efficacy (Bogen-Johnston et al., 2017; Greene and Faulkner, 2002).

The intimacy involved in revealing rather than concealing their identity as a young person living with chronic illness was also a form of trust. Developing and maintaining relationships with individuals who have similar conditions to discuss their unique experience and struggles provides an opportunity to practice disclosing and discussing illness with others (Enimil et al., 2016).

The decision to disclose was not always part of a health management or treatment plan developed by health and social service providers, in the same way that medication adherence or therapeutic interventions would be discussed. As such, young people really had to develop their own disclosure plans, at times alone, adding to their work load. This was compounded by the fact that for young people, disclosure took place within the context of their evolving identities. Moving forward, perhaps role playing for disclosure could help prepare youth for the disclosure process.

\section{Limitations}

While this paper has advanced our understanding of the centrality and spectrum of disclosure for young people living with chronic illness, there are limitations. This study involved participants with a wide age range and did not reveal developmental differences. Moving forward studies would benefit from smaller age groupings in order to gain a deeper understanding of that particular developmental stage. Future studies would also benefit from diversity in terms of ethnic background and gender identity. A longitudinal approach that is able to capture the disclosure spectrum from initial diagnosis onwards would provide an understanding of how the disclosure spectrum changes over time.

\section{Conclusion}

Findings from this study reinforced that disclosure decisions are central to the illness experience for youth with chronic conditions. Youth described disclosure a complex process deeply embedded in their everyday life and requiring ongoing and constant consideration. The variable spectrum of disclosure approached adopted by youth reveals the extent to which disclosure shapes how the youth perceive and present themselves to the world. The findings reinforce that more emphasis on decisions related to disclosing illness in research and clinical care for 
youth with chronic conditions is warranted. Youth living with chronic illness need to be offered responsive supports during when making illness disclosure decisions. Future work that explores possible avenues for support and intervention that facilitate positive disclosure experiences for youth with chronic illness is warranted.

\section{Acknowledgements}

We would like to thank the youth who participated in the study and who shared their time and their experiences.

\section{Declaration of conflicting interests}

The author(s) declared no potential conflicts of interest with respect to the research, authorship, and/or publication of this article.

\section{Funding}

The author(s) disclosed receipt of the following financial support for the research, authorship, and/or publication of this article: RLW was supported by the Canadian Institutes of Health Research (Grant\#: CIHR MOP - 89895) for this study. RLW is supported by a Tier 1 Canadian Research Chair (CRC) in Child and Family Engagement in Health Research and Healthcare (Project \#: 950-231845), Canadian Institutes of Health Research. The funding sources had no role in the conduct of the study, analysis of data, or decision for publication.

\section{ORCID iD}

Roberta Lynn Woodgate (iD https://orcid.org/0000 -0002-7176-2390

\section{Note}

1. Throughout this paper, we use terms such as "children", "youth", and "young people" interchangeably.

\section{References}

Admi H and Shaham B (2007) Living with epilepsy: Ordinary people coping with extraordinary situations. Qualitative Health Research 17(9): 1178-1187.

Ahola Kohut S, Stinson J, Forgeron P, et al. (2016) A qualitative content analysis of peer mentoring video calls in adolescents with chronic illness. Journal of Health Psychology 23(6): 788-799.

Barbour RS (2008) Introducing Qualitative Research: A Student's Guide to the Craft of Doing Qualitative Research. Los Angeles, CA: SAGE.

Barned C, Stinzi A, Mack D, et al. (2016) To tell or not to tell: A qualitative interview study on disclosure decisions among children with inflammatory bowel disease. Social Science \& Medicine 162: 115-123.

Beacham BL and Deatrick JA (2015) Children with chronic conditions: Perspectives on condition management. Journal of Pediatric Nursing 30(1): 25-35.

Benson A, Lambert V, Gallagher P, et al. (2015a) "I don't want them to look at me and think of my illness, I just want them to look at me and see me": Child perspectives on the challenges associated with disclosing an epilepsy diagnosis to others. Epilepsy \& Behavior 53: 83-91.

Benson A, O'Toole S, Lambert V, et al. (2015b) To tell or not to tell: A systematic review of the disclosure practices of children living with epilepsy and their parents. Epilepsy \& Behavior 51: 73-95.

Berlin KS, Sass DA, Hobart DW, et al. (2005) Cystic fibrosis disclosure may minimize risk of negative peer evaluations. Journal of Cystic Fibrosis 4(3): 169-174.

Blake B, Robley L and Taylor G (2012) A lion in the room: Youth living with HIV. Pediatric Nursing 38(6): 311-318.

Bogen-Johnston L, de Visser R, Strauss C, et al. (2017) "That little doorway where i could suddenly start shouting out": Barriers and enablers to the disclosure of distressing voices. Journal of Health Psychology 24(10): 1307-1317.

Charmaz K (1983) The grounded theory method: An explication and interpretation. In: Emerson RM (ed) Contemporary Field Research: A Collection of Readings. Prospect Heights, Illinois: Waveland Press, 109-126.

Charmaz K (1995) Grounded theory. In: Smith JA, Harre R and Van Langenhove L (eds) Rethinking Methods in Psychology. London, UK.: SAGE Publications, 27-65.

Charmaz K (2000) Grounded theory: Objectivist and constructivist methods. In: Denzin NK and Lincoln YS (eds) The Handbook of Qualitative Research, 2nd ed. Thousand Oaks, CA: SAGE Publications, Inc., 509-535.

Charmaz K and Belgrave LL (2012) Qualitative interviewing and grounded theory analysis. 
In: Gubrium JF, Holstein JA, Marvasti AB, et al. (eds) The SAGE Handbook of Interview Research: The Complexity of the Craft, 2 nd ed. London, UK.: SAGE Publications Inc., 347-365.

Dean J, Fenton NE, Shannon S, et al. (2015) Disclosing food allergy status in schools: Health-related stigma among school children in Ontario. Health and Social Care in the Community 24 (5): e43-e52.

DeLong L and Kahn J (2014) Shameful secrets and shame-prone dispositions: How outcome expectations mediate the relation between shame and disclosure. Counselling Psychology Quarterly 27(3): 290-307.

Denny S, de Silva M, Fleming T, et al. (2014) The prevalence of chronic health conditions impacting on daily functioning and the association with emotional well-being among a national sample of high school students. Journal of Adolescent Health 54(4): 410-415.

Duncan RE, Hall AC and Knowles A (2015) Ethical dilemmas of confidentiality with adolescent clients: Case studies from psychologists. Ethics \& Behavior 25(3): 197-221.

Dyson SM, Atkin K, Culley LA, et al. (2010) Disclosure and sickle cell disorder: A mixed methods study of the young person with sickle cell at school. Social Science \& Medicine 70(12): 2036-2044.

Enimil A, Nugent N, Amoah C, et al. (2016) Quality of life among Ghanaian adolescents living with perinatally acquired HIV: A mixed methods study. AIDS Care 28(4): 460-464.

Fair C and Albright J (2012) "Don't tell him you have HIV unless he's 'the one"': Romantic relationships among adolescents and young adults with perinatal HIV infection. AIDS Patient Care \& STDs 26(12): 746-754.

Galano E, Turato ER, Succi RC, et al. (2017) Costs and benefits of secrecy: The dilemma experienced by adolescents seropositive for HIV. AIDS Care 29(3): 394-398.

Gannoni AF and Shute RH (2009) Parental and child perspectives on adaptation to childhood chronic illness: A qualitative study. Clinical Child Psychology and Psychiatry 15(1): 39-53.

Greene K and Faulkner SL (2002) Expected versus actual responses to disclosure in relationships of HIV-positive African American adolescent females. Communication Studies 53(4): 297-317.

Gronholm PC, Thornicroft G, Laurens KR, et al. (2017) Conditional disclosure on pathways to care: Coping preferences of young people at risk of psychosis. Qualitative Health Research 27(12): 1842-1855.

Heyduck K, Bengel J, Farin-Glattacker E, et al. (2015) Adolescent and parental perceptions about asthma and asthma management: A dyadic qualitative analysis. Child: Care, Health and Development 41(6): 1227-1237.

Kaushansky D, Cox J, Dodson C, et al. (2017) Living a secret: Disclosure among adolescents and young adults with chronic illnesses. Chronic Illness 13(1): 49-61.

Kirk S and Hinton D (2019) "I'm not what I used to be": A qualitative study exploring how young people experience being diagnosed with a chronic illness. Child Care Health Development 45(2): 216-226.

Krockow EM, Riviere E and Frosch CA (2019) Improving shared health decision making for children and adolescents with chronic illness: A narrative literature review. Patient Education and Counseling 102(4): 623-630.

Lambert V and Keogh D (2015) Striving to live a normal life: A review of children and young people's experience of feeling different when living with a long term condition. Journal of Pediatric Nursing 30(1): 63-77.

Law GU, Tolgyesi CS and Howard RA (2014) Illness beliefs and self-management in children and young people with chronic illness: A systematic review. Health Psychology Review 8(3): 362-380.

Lee S, Yamazaki M, Harris D, et al. (2015) Social support and human immunodeficiency virus-status disclosure to friends and family: Implications for human immunodeficiency virus-positive youth. Journal of Adolescent Health 57(1): 73-80.

Leeman J, Crandell JL, Lee A, et al. (2016) Family functioning and the well-being of children with chronic conditions: A meta-analysis. Research in Nursing \& Health 39(4): 229-243.

Lincoln YS and Guba EG (1985) Naturalistic Inquiry. Newbury Park, CA: Sage.

Lum A, Wakefield CE, Donnan B, et al. (2017) Understanding the school experiences of children and adolescents with serious chronic illness: A systematic meta-review. Child: Care, Health and Development 43(5): 645-662.

Maes M, Van den Noortgate W, Fustolo-Gunnink SF, et al. (2017) Loneliness in children and adolescents with chronic physical conditions: A meta-analysis. Journal of Pediatric Psychology 42(6): 622-635.

Maslow GR, Haydon A, McRee A-L, et al. (2011) Growing up with a chronic illness: Social suc- 
cess, educational/vocational distress. Journal of Adolescent Health 49(2): 206-212.

Yoder CLMK and Cantrell MA (2019) Childhood disability and educational outcomes: A systematic review. Journal of Pediatric Nursing 45: 37-50.

Miller VA (2009) Parent-child collaborative decision making for the management of chronic illness: A qualitative analysis. Families, Systems, \& Health 27(3): 249-266.

Morse JM and Field PA (1995) Qualitative Research Methods for Health Professionals. Thousand Oaks, CA: Sage Publications.

Perrin JM, Anderson LE and Van Cleave J (2014) The rise in chronic conditions among infants, children, and youth can be met with continued health system innovations. Health Affairs (Project Hope) 33(12): 2099-2105.

Pinquart M (2017) Psychological health of children with chronic physical illness and their parents-Results from meta-analyses/Psychische Gesundheit von chronisch korperlich kranken Kindern und ihren Eltern-Ergebnisse von Metaanalysen. Praxis der Kinderpsychologie und Kinderpsychiatrie 66(9): 656-672

QSR International Pty Ltd. (2018) NVivo 12 Qualitative Data Analysis Software [Software]. Available at: https://www.qsrinternational.com/ nvivo-qualitative-data-analysis-software/home

Reaume SV and Ferro MA (2019) Chronicity of mental comorbidity in children with newonset physical illness. Child: Care, Health and Development 45(4): 559-567.

Russell JK, Strodl E, Connolly J, et al. (2019) A metacognitive intervention of narrative imagery for young people with cystic fibrosis: A feasibility study. Journal of Health Psychology. Epub ahead of print 18 September. DOI: 10.1177/1359105319876336.

Sandelowski M (1995) Sample size in qualitative research. Research in Nursing \& Health 18(2): 179-183.

Saxby N, Beggs S, Battersby M, et al. (2019) What are the components of effective chronic condition self-management education interventions for children with asthma, cystic fibrosis, and diabetes? A systematic review. Patient Education and Counseling 102(4): 607-622.

Silva N, Pereira M, Otto C, et al. (2019) Do 8- to 18-year-old children/adolescents with chronic physical health conditions have worse healthrelated quality of life than their healthy peers? A meta-analysis of studies using the KIDSCREEN questionnaires. Quality of Life Research 28(7): 1725-1750.

Siu GE, Bakeera-Kitaka S, Kennedy CE, et al. (2012) HIV serostatus disclosure and lived experiences of adolescents at the transition clinic of the infectious diseases clinic in kampala, uganda: Qualitative study. AIDS Care 24(5): 606-611.

Sligo J, Jones B, Davies C, et al. (2019) The experiences of young people with chronic illness in New Zealand: A qualitative study. Child: Care, Health and Development 45(5): 660-669.

Stein REK and Jessop DJ (1989) What diagnosis does not tell: The case for a noncategorical approach to chronic illness in childhood. Social Science \& Medicine 29(6): 769-778.

Stein REK and Silver EJ (1999) Operationalizing a conceptually based noncategorical definition: A first look at US children with chronic conditions. Archives of Pediatrics \& Adolescent Medicine 153(1): 68-74.

van Der LJH, Mokkink LB, Grootenhuis MA, et al. (2007) Definitions and measurement of chronic health conditions in childhood: A systematic review. JAMA 297(24): 2741-2751.

Vos T, Barber RM, Bell B, et al. (2015) Global, regional, and national incidence, prevalence, and years lived with disability for 301 acute and chronic diseases and injuries in 188 countries, 1990-2013: A systematic analysis for the global burden of disease study 2013. The Lancet 386(9995): 743-800.

Wakefield CE, McLoone JK, Fleming CAK, et al. (2011) Adolescent cancer and health-related decision-making: An Australian multi-perspective family analysis of appointment attendance and involvement in medical and lifestyle choices. Journal of Adolescent and Young Adult Oncology 1(4): 173-180. 